$\mathrm{DE}$

M E D I C I N A

T R O P I C A L

$\mathrm{DE}$

SÃO PAULO

JOURNAL OF THE SÃO PAULO INSTITUTE OF TROPICAL MEDICINE

(1) Universidade Federal de Mato Grosso do Sul, Hospital Universitário Maria Aparecida Pedrossian, Laboratório de Análises Clínicas, Campo Grande, Mato Grosso do Sul, Brazil

(2) Universidade Federal de Mato Grosso do Sul, Faculdade de Ciências Farmacêuticas, Alimentos e Nutrição, Campo Grande, Mato Grosso do Sul, Brazil

(3)Universidade de São Paulo, Instituto de Medicina Tropical de São Paulo, Laboratório de Micologia Médica (LIM-53), São Paulo, São Paulo, Brazil

(4) Universidade Estadual Paulista Júlio de Mesquita Filho, Faculdade de Medicina, Botucatu, São Paulo, Brazil

(5) Universidade Federal de Mato Grosso do Sul, Faculdade de Medicina, Campo Grande, Mato Grosso do Sul, Brazil

Correspondence to: Anamaria Mello Miranda Paniago Universidade Federal de Mato Grosso do Sul, Faculdade de Medicina, Av. Senador -Fillinto, Muller, 355, CEP 79070-900, Campo Grande, MS, Brazil Tel: +55 67 3345-7804

E-mails: anamaria.paniago@ufms.br; anapaniago@yahoo.com.br

Received: 21 April 2017

Accepted: 22 August 2017

\section{Identification and antifungal susceptibility of Candida species isolated from the urine of patients in a university hospital in Brazil}

\author{
Gláucia Moreira Espíndola Lima1, Maína de Oliveira Nunes', Marilene \\ Rodrigues Chang ${ }^{2}$, Rosianne Assis de Sousa Tsujisaki ${ }^{2}$, Joslaine de Oliveira \\ Nunes $^{2}$, Cleison Ledesma Taira ${ }^{3}$, Danilo Yamamoto Thomaz ${ }^{3}$, Gilda Maria \\ Bárbaro Del Negro ${ }^{3}$, Rinaldo Pôncio Mendes ${ }^{4}$, Anamaria Mello Miranda \\ Paniago $^{5}$
}

\section{ABSTRACT}

The aim of this study was to identify Candida spp. isolated from candiduria episodes at a tertiary hospital in the Midwest region of Brazil, and to determine their susceptibility profiles to antifungal compounds. From May 2011 to April 2012, Candida spp. isolated from 106 adult patients with candiduria admitted to the University Hospital of the Federal University of Mato Grosso do Sul were evaluated. Both, species identification and susceptibility testing with fluconazole-FLC, voriconazole-VRC, and amphotericin B-AmB were carried out using the Vitek 2. To discriminate species of the C. parapsilosis complex, a RAPD-PCR technique using the RPO2 primer was performed. From the total of 106 isolates, $42(39.6 \%)$ C. albicans and 64 (60.4\%) Candida non-albicans (CNA) - 33 C. tropicalis, 18 C. glabrata, 5 C. krusei, 4 C. parapsilosis sensu stricto, 2 C. kefyr, 1 C. lusitaniae, and 1 C. guilliermondii were identified. All isolates were susceptible to AmB and VRC, whereas all C. glabrata isolates presented either resistance $(5.6 \%)$ or dose-dependent susceptibility $(94.4 \%)$ to FLC. The study of Candida spp. and their resistance profiles may help in tailoring more efficient therapeutic strategies for candiduria.

KEYWORDS: Urine infections. Antifungal agents. Nosocomial candiduria. Candida species. Antifungal susceptibility

\section{INTRODUCTION}

The isolation of Candida spp. from urine cultures may indicate colonization or urinary tract infection (candiduria), but it may also be a sign of severe systemic candidiasis or candidemia ${ }^{1-3}$. Candida spp. can reach the urinary tract via the ascending route, from the urethra to the bladder, or by hematogenous spread, as Candida spp. is filtered by the kidneys and excreted in the urine.

The ability to form biofilm and the production of hydrolytic enzymes, which disrupt cell membranes, facilitate the spread of yeasts in the host, causing infection ${ }^{4-6}$. Lesions in the renal pelvis, tubules, and ureters, and formation of a "fungus ball", which blocks and causes injury to the urinary system, are the main complications associated with candiduria, while development of candidemia is unusual ${ }^{14,7}$.

The source of candidiasis in humans is mostly endogenous, as Candida spp. are commensals in the digestive tract of a vast range of healthy people. Some conditions allow these commensal yeasts to become opportunistic, resulting in candidiasis in 
different sites of the body. Previous studies have shown that advanced age, female sex, urinary tract abnormalities, drainage catheters used in hospitalized patients, diabetes, malignancies, as well as the use of broad-spectrum antibiotics, corticosteroids and immunosuppressive agents are high-risk conditions for developing urinary tract infections ${ }^{3,8,9}$. Candiduria is frequently found in critically ill patients, in those who present with metabolic and immunosuppressive diseases, as well as in patients undergoing surgical procedures or facing long hospital stays $^{4,10}$.

A study conducted in Spain revealed that $22 \%$ of critically ill patients hospitalized for more than seven days in intensive care units (ICUs) developed candiduria, and $10-15 \%$ urinary tract infections in the ICU were caused by the genus Candida $^{11}$. In the United States, from years 1995-2001, it was estimated that there was an average of 25,000 cases of candiduria per year. Around one third of hospitalized patients with positive urine cultures for Candida spp were from the ICU, where the use of urinary catheters is frequent ${ }^{12,13}$. Moreover, it was found that a patient in a given ICU who is exposed to four different antibiotics has about a $35 \%$ risk of developing candidemia, and if Candida is isolated from another site, such as in urine, the risk increases to $80 \%{ }^{13}$.

In severe systemic episodes of Candida infections, management of clinical conditions and enhanced patient survival depend on rapid interventions. Thus, correct identification of the pathogen and administration of specific antifungal therapies are crucial for patient recovery ${ }^{1,14,15}$.

The etiology of candiduria varies according to the geographic region, study period, and type of hospital. Candida albicans is the most prevalent candiduria agent; however, Candida non-albicans (CNA) species have been reported worldwide ${ }^{15,16}$.

The emergence of CNA species with reduced susceptibility or intrinsic resistance to antifungal compounds, mainly the azoles, is a major problem due to the increasing use of fluconazole (FLC) in candidiasis therapy ${ }^{7,17}$. In addition, studies conducted in ICU settings have reported that patients with candiduria have increased mortality rates when compared with similar patients without candiduria ${ }^{11}$. Therefore, early and accurate species identification, as well as investigations of antifungal susceptibility profiles of isolates, is indispensable for determining appropriate therapies for treating episodes of recurrent candiduria and/or persistent candidemia related to candiduria.

Therefore, the monitoring of epidemiological data in hospitals across different regions is important for establishing efficient control measures. The aim of this study was to identify the various species of Candida isolated from candiduria episodes in a tertiary hospital in the Midwest region of Brazil, as well as to determine the in vitro susceptibility profiles of these species to various antifungal compounds.

\section{PATIENTS AND METHODS}

\section{Patients}

This study was conducted at the University Hospital, Federal University of Mato Grosso do Sul, Campo Grande, MS, from May 2011 to April 2012. It was approved by the institutional Ethics Committee in Research with Human Beings (process $\mathrm{N}^{\circ}$ 86663, date of approval 08/30/2012). Adult female and male patients who were admitted to any hospital ward and presented with positive urine cultures for Candida spp. at least 1,000 CFU/mL were included in the study.

\section{Isolation and phenotypic identification}

Urine sample sediments were initially seeded in Chromogenic Candida Selective Agar (CHROMagar, DIFCO; Becton Dickinson France S.A., Le Pont de Claix, France) for identification of Candida species. After inoculation, plates were incubated for $24-48 \mathrm{~h}$ at $30^{\circ} \mathrm{C}$ and colonies were identified based on the chromogenic reaction produced, according to the standard instruction from the manufacturers.

The confirmation of Candida species identification and the antifungal susceptibility was performed using the automated Vitek 2 system (bioMérieux, Marcy-l'Etoile, France). From each sample, a yeast suspension was prepared in sterile saline $(0.9 \%)$, using the densitometer (Densichektm Vitek 2). Yeast suspensions were added and incubated at $35.5^{\circ} \mathrm{C}$ for 18 to $24 \mathrm{~h}$. The equipment classified the final reading and biochemical differentiation reactions as excellent.

Differentiation of the $C$. parapsilosis complex species was performed by random amplified polymorphic DNA-polymerase chain reaction (RAPD-PCR) with the RPO2 primer (5'-GCGATCCCCA-3'), according to Rycovska et al. ${ }^{18}$.

C. parapsilosis isolates were re-suspended in saline with turbidity equivalent to 0.5 in the McFarland scale, centrifuged at $5000 \mathrm{x} \mathrm{g}$ and the pellets were subjected to DNA extraction. The final volume of reactions was $50 \mu \mathrm{L}$ containing $20 \mathrm{ng}$ of genomic DNA of each sample, $1.5 \mathrm{U}$ of GoTaq DNA polymerase (Promega Co., USA), $10 \mu \mathrm{L}$ of $5 \mathrm{x}$ concentrated buffer $(1.5 \mathrm{mM} \mathrm{MgCl}, 200 \mu \mathrm{M}$ dNTP 
and $1 \mu \mathrm{M}$ of primer RPO2). Amplifications were performed in a Veriti Thermocycler (Life Technologies, USA). After a first cycle of denaturation for 2 min at $94{ }^{\circ} \mathrm{C}, 35$ cycles of denaturation at $94{ }^{\circ} \mathrm{C}$ for $1 \mathrm{~min}$, annealing at $36{ }^{\circ} \mathrm{C}$ for $1 \mathrm{~min}$, and extension at $72{ }^{\circ} \mathrm{C}$ for $75 \mathrm{~s}$ were performed, with a final extension step of $10 \mathrm{~min}$ at $72{ }^{\circ} \mathrm{C}$.

Reference strains ATCC (American Type Culture Collection) were used as positive controls [C. parapsilosis (ATCC 22019), C. orthopsilosis (ATCC 96141) and C. metapsilosis (ATCC 96143)]. Amplified DNA products were separated by electrophoresis in a $1.5 \%$ agarose gel (Invitrogen, USA) with Tris-EDTA pH 8.0 buffer, stained with GelRed (Biotium, USA).

\section{Antifungal susceptibility testing}

Determination of the minimum inhibitory concentration (MIC) was performed using the automated Vitek 2 (bioMérieux) system with the following antifungal drugs: amphotericin B (AmB), FLC, and voriconazole (VRC).

The minimum inhibitory concentration (MIC) breakpoints used for fluconazole and voriconazole were those suggested by Laboratory Standards Institute's M27-S4 document ${ }^{19}$, for C. albicans, C. tropicalis and C. parapsilosis $\leq 2 \mu \mathrm{g} / \mathrm{mL}$ were susceptible, $4 \mu \mathrm{g} / \mathrm{mL}$ were susceptible dose-dependent (SDD) and $\geq 8 \mu \mathrm{g} / \mathrm{mL}$ were resistant. For C. glabrata isolates, $\leq 32 \mu \mathrm{g} / \mathrm{mL}$ were SDD and $\geq 64 \mu \mathrm{g} / \mathrm{mL}$ were resistant. Due to a lack of consensus about the definition of MIC breakpoints for amphotericin B, we considered values suggested by previous publications ${ }^{20}$, MICs $\leq 1 \mu \mathrm{g} / \mathrm{mL}$ as susceptible and MICs $\geq 2 \mu \mathrm{g} / \mathrm{mL}$ as resistant.

From the growth on Sabouraud dextrose agar for $24 \mathrm{~h}$, a yeast suspension with turbidity equivalent to 0.5 in the MacFarland was prepared to test the performance of the broth microdilution test.

The MIC values of FLC (Pfizer) were confirmed by the microdilution broth technique ${ }^{21}$ using the RPMI-1640 culture medium (Vitrocell). The stock solution of FLC $(5120 \mu \mathrm{g} / \mathrm{mL})$ was thawed at room temperature and diluted in a twofold dilution ratio.

Flat-bottom microdilution plates containing $100 \mu \mathrm{L}$ of the twofold serial dilutions of FLC were inoculated with $100 \mu \mathrm{L}$ of Candida suspensions. The final inoculum concentration was 0.5 to $2.5 \times 10^{3} \mathrm{CFU} / \mathrm{mL}$ and the final ranges of the tested FLC dilutions were 0.25 to $128 \mu \mathrm{g} / \mathrm{mL}$. Microdilution plates were incubated at $37^{\circ} \mathrm{C}$ for $24 \mathrm{~h}$. Each sample was tested in triplicate.

The quality control strains C. krusei (ATCC 6258) and C. parapsilosis (ATCC 22019) were provided by the Central Laboratory of Mato Grosso do Sul (LACEN-MS).

\section{Statistical analysis}

Statistical analysis was performed using the Minitab software version 14 (Minitab Inc., State College, PA, USA). To determine the association between variables, the chisquared $\left(x^{2}\right)$ or the Fisher's exact test were used; a $p$-value $<0.05$ was considered significant.

\section{RESULTS}

\section{Patients' epidemiological characteristics}

During the study period, 106 adult patients were diagnosed with candiduria; 58 (54.7\%) patients were female and $48(45.3 \%)$ were male. The patients' ages ranged from 19 to 93 years, with a median of 68 years. Twelve $(11.3 \%)$ patients were aged between 18 and 30 years, 25 (23.6\%) between 31 and 60 years, and $69(65.1 \%)$ were older than 60 years. Regarding the hospital setting, 33 patients (31.1\%) were admitted to the ICU, 33 (31.1\%) to emergency medical care, $20(19.0 \%)$ to internal medical clinical wards, eight $(7.5 \%)$ to the coronary unit, five $(4.7 \%)$ to the surgical units, four $(3.8 \%)$ to the maternity ward, two $(1.9 \%)$ to the infectious diseases ward, and one patient $(0.9 \%)$ to the renal unit.

\section{Candida species}

The CNA species predominated, occurring in 64 (60.4\%) patients. There was no identification of more than one species in the same patient. CNA was more likely to be observed in patients older than 60 years when compared to those younger than 60 years $(68.1 \%$ versus 48.9\%, respectively; $P=0.026$ ). C. albicans, $C$. tropicalis, and $C$. glabrata species were the most frequently isolated, accounting for $87.7 \%$ of all infections. The frequency of C. albicans (39.6\%) and C. tropicalis (31.1\%) cases did not differ from one another, and they were more frequently found than C. glabrata $(17.0 \%)([$ C. albicans $=$ C. tropicalis $]>C$. glabrata; $P<0.05)$.

The four samples phenotypically identified as C. parapsilosis (sensu lato) weremolecularly characterized as $C$. parapsilosis (sensu stricto) after performing the RAPD assay (Figure 1).

\section{Antifungal susceptibility}

All isolates showed MIC $=1 \mu \mathrm{g} / \mathrm{mL}$ for $\mathrm{AmB}$ and an $\mathrm{MIC}=0.012 \mu \mathrm{g} / \mathrm{mL}$ for VRC; therefore, they were considered susceptible. Regarding FLC, C. krusei and all C. glabrata isolates showed MIC values that were 


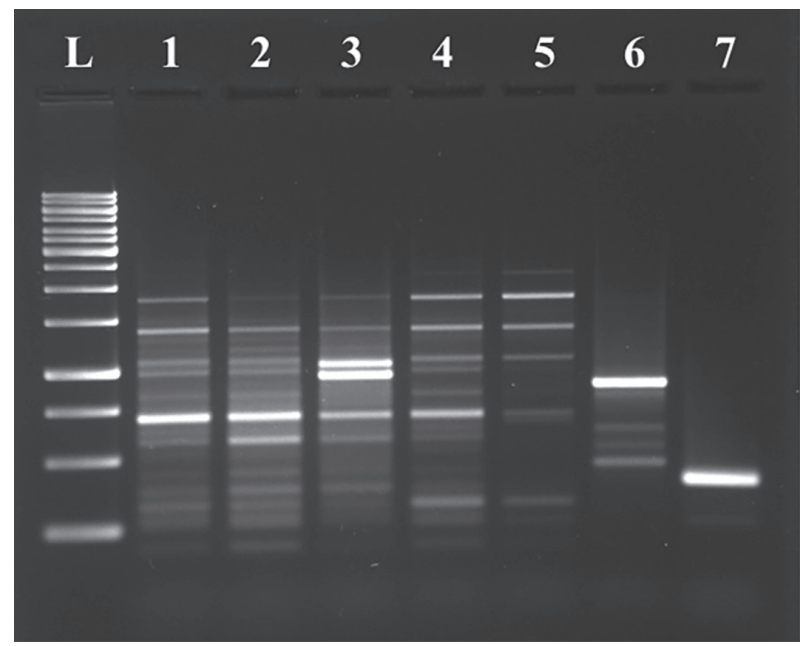

Figure 1 - Agarose gel showing the RAPD products obtained from Candida parapsilosis complex isolates and ATCC strains. Lane L - 100 bp molecular weight marker (GE Healthcare); lanes 1-4 - Candida parapsilosis complex isolates, all identified as Candida parapsilosis sensu stricto; lane 5 - C. parapsilosis sensu stricto (ATCC 22019); lane 6 - C. orthopsilosis (ATCC 96141); lane 7 - C. metapsilosis (ATCC 96143). RAPD= random amplified polymorphic DNA; ATCC=American Type Culture Collection

compatible with the SDD or R categories (Table 1). C. kefyr, C. guilliermondii, and C. lusitaniae were $100 \%$ susceptible (MIC $=2 \mu \mathrm{g} / \mathrm{mL}$ ).

We did not observe associations among any of the studied variables with FLC resistance or SDD to FLC (Table 2). However, the mean number of C. glabrata isolated from ICU patients was higher than the numbers obtained from patients admitted to all the other hospital wards ( $22.7 \%$ versus $7.5 \%$, respectively; $P=0.043$ ).

\section{DISCUSSION}

The correct identification of yeasts isolated from the urine cultures of hospitalized patients, as well as the yeasts' antifungal susceptibility profiles, are relevant for determining appropriate treatments and urinary tract infection management ${ }^{1,3}$. This study revealed a greater proportion of CNA isolates from urine samples, which points to the emergence of strains resistant to FLC in our hospital.

There was a higher frequency of candiduria in women. Previous studies have shown that up to $30 \%$ of healthy women may experience persistent vulvovaginal colonization by Candida spp. This colonization, facilitated by the female anatomy, can ascend to the bladder and kidneys, causing urinary tract infections ${ }^{22-24}$.

Similar to other reports, most patients in our study were over 60 years of age. In general, older adults tend to exhibit natural modifications of the immune system, resulting in longer hospital stays in critical care units and the need of urinary catheters ${ }^{1,8,24-26}$.

Most patients in our study that tested positive for candiduria were hospitalized in ICU or emergency units, where most of them are generally submitted to invasive procedures and monitored with bladder catheters. These conditions may lead to the rupture of anatomical barriers, resulting in changes of the native host microbiota ${ }^{2,4,10,20}$.

It is generally accepted that urine cultures with at least $100,000 \mathrm{CFU} / \mathrm{mL}$, with or without pyuria, can serve as an alert to a possible urinary tract infection, which is initially presumed as a bacterial infection ${ }^{5,8,27}$. There is no consensus among the authors regarding the cutoff point for interpreting urine cultures containing fungi; however, a minimum count of $1,000 \mathrm{CFU} / \mathrm{mL}$ in symptomatic patients has been considered a positive infection ${ }^{1,11}$. The presence of candiduria in critically ill patients has been regarded as an indicator of invasive candidiasis ${ }^{27}$.

The increased prevalence of CNA as a cause of

Table 1 - Candida species and antifungal susceptibility in urine isolates $(n=106)$

\begin{tabular}{|c|c|c|c|c|c|c|c|c|c|}
\hline \multirow{2}{*}{ Candida species (n; \%) } & \multicolumn{3}{|c|}{ Amphotericin B (\%) } & \multicolumn{3}{|c|}{ Fluconazole (\%) } & \multicolumn{3}{|c|}{ Voriconazole (\%) } \\
\hline & $\mathrm{R}$ & SDD & $S^{*}$ & $\mathrm{R}$ & SDD & $S^{\star *}$ & $\mathrm{R}$ & SDD & $S^{* * *}$ \\
\hline Candida albicans (42; 39.6) & 0 & 0 & 100 & 0 & 0 & 100 & 0 & 0 & 100 \\
\hline Candida tropicalis $(33 ; 31.1)$ & 0 & 0 & 100 & 0 & 0 & 100 & 0 & 0 & 100 \\
\hline Candida glabrata $(18 ; 17.0)$ & 0 & 0 & 100 & $5.6^{(a)}$ & $94.4^{(\mathrm{b})}$ & 0 & 0 & 0 & 100 \\
\hline Candida krusei $(5 ; 4.7)$ & 0 & 0 & 100 & 100 & 0 & 0 & 0 & 0 & 100 \\
\hline Candida parapsilosis $(4 ; 3.8)$ & 0 & 0 & 100 & 0 & 0 & 100 & 0 & 0 & 100 \\
\hline Candida kefyr $(2 ; 1.9)$ & 0 & 0 & 100 & 0 & 0 & 100 & 0 & 0 & 100 \\
\hline Candida guilliermondii $(1 ; 0.9)$ & 0 & 0 & 100 & 0 & 0 & 100 & 0 & 0 & 100 \\
\hline Candida lusitaniae $(1 ; 0.9)$ & 0 & 0 & 100 & 0 & 0 & 100 & 0 & 0 & 100 \\
\hline
\end{tabular}

$\mathrm{R}=$ resistant; SDD = susceptible dose dependent; $\mathrm{S}=$ susceptible; $\mathrm{MIC}=$ minimal inhibitory concentration. ${ }^{*}(\mathrm{MIC} \leq 1 \mu \mathrm{g} / \mathrm{mL})$; ${ }^{* *}(\mathrm{MIC} \leq 2 \mu \mathrm{g} / \mathrm{mL}),{ }^{* * *}(\mathrm{MIC} \leq 0.12 \mu \mathrm{g} / \mathrm{mL}) ;{ }^{(a)}(\mathrm{MIC}>64 \mu \mathrm{g} / \mathrm{mL}) ;{ }^{(b)}(\mathrm{MIC} \leq 32 \mu \mathrm{g} / \mathrm{mL})$. 
Table 2 - Demographic variables and susceptibility to fluconazole $(n=106)$

\begin{tabular}{|c|c|c|c|c|}
\hline \multirow{2}{*}{ Variables } & & Resistant or SDD $(n=23)$ & Susceptible $(n=83)$ & \multirow{2}{*}{$p$-value } \\
\hline & & n (\%) & n (\%) & \\
\hline \multirow[t]{2}{*}{ Inpatient unit } & $\mathrm{ER} / \mathrm{ICU}$ & $18(78.3)$ & $48(57.8)$ & 0.074 \\
\hline & Other & $5(21.7)$ & $35(42.2)$ & \\
\hline \multirow[t]{2}{*}{ Age $\geq 60$ years } & No & $6(26.1)$ & $31(37.3)$ & 0.316 \\
\hline & Yes & $17(73.9)$ & $52(62.7)$ & \\
\hline \multirow[t]{2}{*}{ Sex } & Female & $14(60.9)$ & $44(53.0)$ & 0.503 \\
\hline & Male & $9(39.1)$ & $39(47.0)$ & \\
\hline \multirow[t]{2}{*}{$\mathrm{CFU} / \mathrm{mL}$} & $>100.000$ & $22(95.7)$ & $70(84.3)$ & $0.294^{*}$ \\
\hline & $\leq 100.000$ & $1(4.3)$ & $13(15.7)$ & \\
\hline \multirow[t]{2}{*}{ Leukocytes >5/field } & No & $2(9.1)$ & $13(15.7)$ & 0.732 \\
\hline & Yes & $20(90.9)$ & $70(84.3)$ & \\
\hline
\end{tabular}

*Fisher's exact test. $\mathrm{N}=$ number of patients; $\mathrm{SDD}=$ susceptible dose-dependent; $\mathrm{ER}=$ emergency room; ICU= intensive care unit; $\mathrm{CFU}=$ colony-forming units.

candidiasis in hospital settings has been observed around the world at any site of infection, including the urinary $\operatorname{tract}^{3,28,29}$. The importance of this fact is that CNA species are likely to be resistant to antifungal agents, which reinforces the need to identify various Candida species, as well as to assess their susceptibility profile to antifungal agents in hospitalized patients ${ }^{13,17,30}$.

C. albicans, C. tropicalis, and C. glabrata were the main isolated species in our investigation. The comparison of the Candida species prevalence found in the present investigation with other eight Brazilian studies ${ }^{16,31-37}$ on candiduria revealed a predominance of $C$. albicans in seven of them ${ }^{16,31-36}$ and, in the second position, $C$. tropicalis in three studies ${ }^{16,33,35}$, the same behavior we observed in our study. In one study $C$. tropicalis was the most frequent ${ }^{37}$. The prevalence of $C$. parapsilosis, which was $4.7 \%$ in our study, in the other studies ranged from zero to $17.4 \%{ }^{16,31-37}$. The evaluation of studies carried out in different regions of the country revealed a great similarity in the prevalence of Candida species among studies performed in the Midwest region ${ }^{16,31,32}$ and those from the Southeast among themselves ${ }^{34,35,37}$. C. albicans is the most frequently found species in the digestive tracts of healthy people, and it has greater pathogenic mechanisms when compared to other Candida spp. ${ }^{5,38}$. Emerging $C$. tropicalis causes urinary tract infections primarily in patients presenting chronic degenerative diseases and/or trauma ${ }^{17,30,39}$.

The prevalence of $C$. glabrata in our study (17\%) was higher than the one found in other earlier Brazilian reports, which ranged from 0 to $12.5 \% \%^{16,31-35,37}$. Our data corroborate previous findings, which have shown that $C$. glabrata has emerged in tertiary hospitals in recent years, both in Brazil and in other countries ${ }^{8,40}$.
The $C$. parapsilosis complex has emerged as a primary agent of urinary tract infections in hospitalized patients due to its capacity to form biofilm ${ }^{36,41}$. Not all members of the $C$. parapsilosis complex are virulent; among them, C. metapsilosis appears to present the lowest virulence, but this evidence is still limited ${ }^{42}$. This reinforces the importance of differentiating $C$. parapsilosis in clinical studies, including isolates from other anatomic sites ${ }^{43}$. In our study, the four (3.8\%) isolates that belong to the $C$. parapsilosis complex were identified as $C$. parapsilosis (sensu stricto).

Several studies have shown the emergence of antifungal resistance, especially FLC resistance in C. albicans ${ }^{44}$; however, all of the $C$. albicans isolates were susceptible to AmB, FLC, and VRC. Moreover, the non-albicans species were also susceptible to the tested drugs, except $C$. krusei, which is intrinsically resistant to FLC. Furthermore, all isolates of $C$. glabrata were also resistant or SDD to this azole. Resistance to FLC or AmB has already been described in C. glabrata $^{27}$ and C. tropicalis $^{30}$.

In Brazil, five studies from different regions evaluated the susceptibility to FLC of Candida species isolated

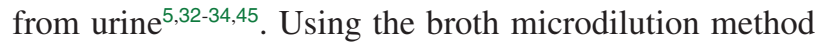
to evaluate $C$. albicans isolates, one study showed no resistance to $\mathrm{FLC}^{34}$, as did ours, and another showed $15.0 \%$ of resistance ${ }^{5}$. Using the disk diffusion, $7.5 \%{ }^{5}$ and $75 \%{ }^{33}$ of resistance to FLC were observed. The isolates of $C$. tropicalis were $100 \%$ sensitive to FLC, using the broth microdilution method, in two studies ${ }^{34,45}$ and $12.5 \%$ of resistance in one ${ }^{5}$, confirming our findings. Using the disk diffusion method, high rates of FLC resistance were observed $^{32,33}$. Regarding C. parapsilosis, there was no resistance to $\mathrm{FLC}^{34}$, as in the present study. We have also observed variations in the susceptibility profile of Candida 
species to the most common antifungal agents of hospital use, especially to FLC, depending on the Candida species, methodology used, number of cases studied and year of publication.

The increasing prevalence rates of these species, which feature high MIC values for FLC, have already been reported in North America and Europe $e^{1,8,44,46}$. Some reports have demonstrated that this change in the susceptibility profile to FLC may be a consequence of the indiscriminate use of this antifungal agent in nosocomial settings ${ }^{8,44,47}$. In this study, the patients' previous use of FLC was not investigated. In fact, all C. parapsilosis (sensu stricto) isolates were susceptible to AmB, FLC, and VRC, corroborating the findings of other authors ${ }^{42,48}$.

In serious and systemic infections, the patient's survival depends on the early intervention and specific antifungal therapy. Delays to initiate an effective antifungal therapy among hospitalized patients is associated with high mortality ${ }^{1}$. Candiduria in seriously ill patients should be carefully evaluated, as this medical condition may be the only indicator of invasive candidiasis. Its detection increases the chances of successful treatment and enhances the patients' survival ${ }^{4,17}$.

\section{ACKNOWLEDGMENTS}

We wish to thank the pharmaceutical-biochemical team, including Débora de Souza Olartechea de Alencar, Dijane Cristina Barros Rosa Costa, and Kelly Fillipin, for providing their technical support at the mycology laboratory of LAC-HUMAP/UFMS. This research received financial support from FUNDECT.

\section{AUTHORS CONTRIBUTIONS}

GMEL: study design; collection, analysis, interpretation of data; paper writing. MON: data collection and analysis. MRC: data interpretation and paper writing. RAST: data collection and analysis. JON: data collection and analysis. CLT: molecular biology data analysis and interpretation. DYT: molecular biology data analysis, interpretation and paper writing. GMBDN: data analysis, interpretation and paper writing. RPM study design, data analysis, interpretation and paper writing. AMMP study design, data analysis, interpretation and paper writing.

\section{REFERENCES}

1. Kauffman CA. Diagnosis and management of fungal urinary tract infection. Infect Dis Clin North Am. 2014;28:61-74.

2. Huang PY, Hung MH, Shie SS, Su LH, Chen KY, Ye JJ, et al. Molecular concordance of concurrent Candida albicans candidemia and candiduria. Diagn Microbiol Infect Dis. 2013;76:382-4.

3. Colombo AL, Guimarães T. Candidúria: uma abordagem clínica e terapêutica. Rev Soc Bras Med Trop. 2007;40:332-7.

4. Fisher JF, Kavanagh K, Sobel JD, Kauffman CA, Newman CA. Candida urinary tract infection: pathogenesis. Clin Infect Dis. 2011;52 Suppl 6:S437-51.

5. Freitas AR, Baeza LC, Faria MG, Dota KF, Godoy Martínez P, Svidzinski TI. Yeasts isolated from nosocomial urinary infections: antifungal susceptibility and biofilm production. Rev Iberoam Micol. 2014;31:104-8.

6. Sardi JC, Duque C, Mariano FS, Peixoto IT, Höfling JF, Gonçalves RB. Candida spp. in periodontal disease: a brief review. J Oral Sci. 2010;52:177-85.

7. Sobel JD, Fisher JF, Kauffman CA, Newman CA. Candida urinary tract infections - Epidemiology. Clin Infect Dis. 2011;52 Suppl 6:S433-6.

8. Colombo AL, Garnica M, Aranha Camargo LF, Cunha CA, Bandeira AC, Borghi D, et al. Candida glabrata: an emerging pathogen in Brazilian tertiary care hospitals. Med Mycol. 2013;51:38-44.

9. Pappas PG, Kauffman CA, Andes D, Benjamin DK Jr, Calandra TF, Edwards JE Jr, et al. Clinical practice guidelines for the management of candidiasis: 2009 update by the Infectious Diseases Society of America. Clin Infect Dis. 2009;48:503-35.

10. Chenoweth CE, Gould CV, Saint S. Diagnosis, management, and prevention of catheter-associated urinary tract infections. Infect Dis Clin North Am. 2014;28:105-19.

11. Alvarez-Lerma F, Nolla-Salas J, León C, Palomar M, Jordá $\mathrm{R}$, Carrasco N, et al. Candiduria in critically ill patients admitted to intensive care medical units. Intensive Care Med. 2003;29:1069-76.

12. Shay AC, Miller LG. An estimate of the incidence of Candiduria among hospitalized patients in the United States. Infect Control Hosp Epidemiol. 2004;25:894-5.

13. Pfaller MA, Castanheira M. Nosocomial candidiasis: antifungal stewardship and the importance of rapid diagnosis. Med Mycol. 2016;54:1-22.

14. Mishra NN, Ali S, Shukla PK. Arachidonic acid affects biofilm formation and PGE2 level in Candida albicans and nonalbicans species in presence of subinhibitory concentration of fluconazole and terbinafine. Braz J Infect Dis. 2014;18:28793.

15. Yashavanth R, Shiju MP, Bhaskar UA, Ronald R, Anita KB. Candiduria: prevalence and trends in antifungal susceptibility in a tertiary care hospital of Mangalore. J Clin Diagn Res. 2013;7:2459.

16. Kobayashi CC, Fernandes OF, Miranda KC, Sousa ED, Silva MR. Candiduria in hospital patients: a study prospective. Mycopathologia. 2004;158:49-52. 
17. Singla N, Gulati N, Kaistha N, Chander J. Candida colonization in urine samples of ICU patients: determination of etiology, antifungal susceptibility testing and evaluation of associated risk factors. Mycopathologia. 2012;174:149-55.

18. Rycovska A, Valach M, Tomaska L, Bolotin-Fukuhara M, Nosek J. Linear versus circular mitochondrial genomes: intraspecies variability of mitochondrial genome architecture in Candida parapsilosis. Microbiology. 2004;150:1571-80.

19. Clinical and Laboratory Standard Institute. Reference method for broth dilution antifungal susceptibility testing of yeasts; 4th Informational Supplement. CLSI document M27-S4. Wayne: CLSI; 2012.

20. Nguyen MH, Clancy CJ, Yu VL, Yu YC, Morris AJ, Snydman DR, et al. Do in vitro susceptibility data predict the microbiologic response to amphotericin B? Results of a prospective study of patients with Candida fungemia. J Infect Dis. 1998; 177:425-30.

21. Clinical and Laboratory Standards Institute. Reference method for broth dilution antifungal susceptibility testing of yeasts; approved standard M27-A3. 3rd ed. Wayne: CLSI; 2008.

22. Morace G, Borghi E. Fungal infections in ICU patients: epidemiology and the role of diagnostics. Minerva Anestesiol. 2010;76:950-6.

23. Achkar JM, Fries BC. Candida infections of the genitourinary tract. Clin Microbiol Rev. 2010;23:253-73.

24. Colodner R, Nuri Y, Chazan B, Raz R. Community-acquired and hospital-acquired candiduria: comparison of prevalence and clinical characteristics. Eur J Clin Microbiol Infect Dis. 2008;27:301-5.

25. Fraisse T, Lachaud L, Sotto A, Lavigne JP, Cariou G, Boiteux JP, et al. Recommandations du comité d'infectiologie de l'AFU. Diagnostic, traitement et suivi des candiduries. Prog Urol. 2011;21:314-21.

26. Valenza G, Strasen J, Schäfer F, Frosch M, Kurzai O, Abele-Horn M. Evaluation of new colorimetric vitek 2 yeast identification card by use of different source media. J Clin Microbiol. 2008;46:3784-7.

27. Kauffman CA, Fisher JF, Sobel JD, Newman CA. Candida urinary tract infections - Diagnosis. Clin Infect Dis. 2011;52 Suppl 6:S452-6.

28. Chang MR, Correia FP, Costa LC, Xavier PC, Palhares DB, Taira DL, et al. Candida bloodstream infection: data from a teaching hospital in Mato Grosso do Sul, Brazil. Rev Inst Med Trop Sao Paulo. 2008;50:265-8.

29. Klotz SA, Chasin BS, Powell B, Gaur NK, Lipke PN. Polymicrobial bloodstream infections involving Candida species: analysis of patients and review of the literature. Diagn Microbiol Infect Dis. 2007;59:401-6.

30. Kothavade RJ, Kura MM, Valand AG, Panthaki MH. Candida tropicalis: its prevalence, pathogenicity and increasing resistance to fluconazole. J Med Microbiol. 2010;59:873-80.
31. Passos XS, Sales WS, Maciel PJ, Costa CR, Miranda KC, Lemos JA, et al. Candida colonization in intensive care unit patients' urine. Mem Inst Oswaldo Cruz. 2005;100:925-8.

32. Sousa IA, Braoios A, Santos TG, Lima JA, Costa RM. Candiduria in adults and children: prevalence and antifungal susceptibility in outpatient of Jataí-GO. J Bras Patol Med Lab. 2014;50:25964.

33. Menezes EA, Barbosa AC, Cunha MC, Mendes LG, Cunha FA. Suscetibilidade a antifúngicos e fatores de virulência de Candida spp. isoladas em Russas, Ceará. Rev Bras Anal Clin. 2016;48:33-8.

34. Neufeld PM, Melhem MS, Szeszs MW, Ribeiro MD, Amorim EL, Silva M, et al. Nosocomial candidiasis in Rio de Janeiro State: distribution and fluconazole susceptibility profile. Braz J Microbiol. 2015;46:477-84.

35. Silva EH, Ruiz LS, Matsumoto FE, Auler ME, Giudice MC, Moreira D, et al. Candiduria in a public hospital of São Paulo (1999-2004): characteristics of the yeast isolates. Rev Inst Med Trop Sao Paulo. 2007;49:349-53.

36. Carvalho M, Guimarães CM, Mayer Jr JR, Bordignon GP, Queiroz-Telles F. Hospital-associated funguria: analysis of risk factors, clinical presentation and outcome. Braz J Infect Dis. 2001;5:313-8.

37. Oliveira RD, Maffei CM, Martinez R. Infecção urinária hospitalar por leveduras do gênero Candida. Rev Assoc Med Bras. 2001;47:231-5.

38. Hiller E, Zavrel M, Hauser N, Sohn K, Burger-Kentischer A, Lemuth $\mathrm{K}$, et al. Adaptation, adhesion and invasion during interaction of Candida albicans with the host--focus on the function of cell wall proteins. Int J Med Microbiol. 2011;301:384-9.

39. Jain N, Mathur P, Misra MC, Behera B, Xess I, Sharma SP. Rapid identification of yeast isolates from clinical specimens in critically ill trauma ICU patients. J Lab Physicians. 2012;4:30-4.

40. Bougnoux ME, Kac G, Aegerter P, d'Enfert C, Fagon JY, Group CS. Candidemia and candiduria in critically ill patients admitted to intensive care units in France: incidence, molecular diversity, management and outcome. Intensive Care Med. 2008;34:292-9.

41. Tavanti A, Davidson AD, Gow NA, Maiden MC, Odds FC. Candida orthopsilosis and Candida metapsilosis spp. nov. to replace Candida parapsilosis groups II and III. J Clin Microbiol. 2005;43:284-92.

42. Silva AP, Miranda IM, Lisboa C, Pina-Vaz C, Rodrigues AG. Prevalence, distribution, and antifungal susceptibility profiles of Candida parapsilosis, C. orthopsilosis, and C. metapsilosis in a tertiary care hospital. J Clin Microbiol. 2009;47:2392-7.

43. Moris DV, Melhem MS, Martins MA, Souza LR, Kacew S, Szeszs MW, et al. Prevalence and antifungal susceptibility of Candida parapsilosis complex isolates collected from oral cavities of HIV-infected individuals. J Med Microbiol. 2012;61:1758-65. 
44. Pfaller MA, Diekema DJ, Gibbs DL, Newell VA, Ellis D, Tullio V, et al. Results from the ARTEMIS DISK Global Antifungal Surveillance Study, 1997 to 2007: a 10.5-year analysis of susceptibilities of Candida species to fluconazole and voriconazole as determined by CLSI standardized disk diffusion. J Clin Microbiol. 2010;48:1366-77.

45. Almeida AA, Nakamura SS, Fiorini A, Grisolia AB, Svidzinski TI, Oliveira KM. Genotypic variability and antifungal susceptibility of Candida tropicalis isolated from patients with candiduria. Rev Iberoam Micol. 2015;32:153-8.

46. Tumbarello M, Sanguinetti M, Trecarichi EM, La Sorda M, Rossi M, de Carolis E, et al. Fungaemia caused by Candida glabrata with reduced susceptibility to fluconazole due to altered gene expression: risk factors, antifungal treatment and outcome. J Antimicrob Chemother. 2008;62:1379-85.

47. Lee I, Fishman NO, Zaoutis TE, Morales KH, Weiner MG, Synnestvedt M, et al. Risk factors for fluconazole-resistant Candida glabrata bloodstream infections. Arch Intern Med. 2009;169:379-83.

48. Lockhart SR, Messer SA, Pfaller MA, Diekema DJ. Geographic distribution and antifungal susceptibility of the newly described species Candida orthopsilosis and Candida metapsilosis in comparison to the closely related species Candida parapsilosis. J Clin Microbiol. 2008;46:2659-64. 